\title{
Outcome of Preterm Labour in SSMC Mitford Hospital, Dhaka.
}

\author{
Mamata Manjari ${ }^{1}$, Lipika Ghosh ${ }^{2}$, Rokhshana Khatun ${ }^{3}$, Jahanara Akter ${ }^{4}$, \\ Md. Mohim Ibn Sina ${ }^{*}$, Mohammad Mizanoor Rahman ${ }^{6}$
}

\begin{abstract}
:
Introduction: : Preterm birth as a consequence of preterm labour is the major clinical problem associated with perinatal mortality, serious neonatal morbidity and moderate to severe childhood disability and two-thirds of all perinatal deaths. Moreover, preterm labour comprises a large number of low birth weight babies. Global incidence of preterm labour is $5-10 \%$ of all births. The aim of this study was to determine the clinical profile and to find out pregnancy outcomes of preterm labour. Materials \& Methods: This cross-sectional study was conducted in Sir Salimullah Medical College Mitford Hospital, Dhaka from January 2005 to December 2005. A total 103 gravid women who got admitted with established premature labour pain were included as study patients. Preterm labour associated with severe pre-eclampsia, eclampsia, antepartum haemorrhage and intrauterine fetal death were excluded. Data were collected in a pre-designed questionnaire and analyzed by SPSS software. Results: Incidence of preterm labour was found 6.3\%. Among maternal morbidities, puerperal sepsis found to be highest (14.56\%) followed by UTI (7.77\%), PPH $(6.80 \%)$, wound infection $(5.83 \%)$ and retained placenta $(3.88 \%)$. This study found perinatal mortality $32.0 \%$ and morbidity $49.5 \%$ of which RDS contributed highest $(24.27 \%)$ followed by neonatal jaundice (11.65\%), septicemia (8.73\%), neonatal convulsion (2.91\%) and umbilical sepsis (1.94\%). Conclusion: Preterm labor followed by preterm birth significantly contributes to maternal morbidity and perinatal morbidity and mortality.
\end{abstract}

Key words: Preterm labour, Preterm birth.

Number of Tables: 07;Number of References: 20; Number of Correspondences: 04.

1. Dr. Mamata Manjari

Assistant Professor

Department of Obstetrics \& Gynaecology

Colonel Malek Medical College, Manikganj.

\section{Dr. Lipika Ghosh}

Assistant Professor

Department of Obstetrics \& Gynaecology

Colonel Malek Medical College, Manikganj.

\section{Dr. Rokhshana Khatun}

Assistant Professor

Department of Obstetrics \& Gynaecology

Colonel Malek Medical College, Manikganj.

4. Dr. Jahanara Akter

Assistant Professor

Department of Obstetrics \& Gynaecology

Institute of Child and Mother Health (ICMH), Matuail, Dhaka.

*5. Corresponding Author: Dr. Md. Mohim Ibn Sina

Assistant Surgeon

Upazila Health Complex (UHC),

Debidwar, Cumilla.

E-mail: misina_ssmc@yahoo.com

Mobile: 01842040170

6. Dr. Mohammad Mizanoor Rahman

Associate Professor and Head

Department of Anesthesiology

ICMH, Matuail, Dhaka.

\section{Introduction}

One of the most sensitive indicators of a nation's commitment to its people is the rate of perinatal mortality. Preterm labour (PTL) is one of the important causes of prematurity that accounts for $50-70 \%$ of all neonatal mortality and morbidity and two-thirds of all perinatal deaths worldwide ${ }^{1-3}$. Preterm delivery is a major obstetric and public health problem in developing countries which is easily demonstrated by virtue of its contribution to total perinatal mortality. Each year about 8 million perinatal deaths occur worldwide and $98 \%$ of them are in the developing countries ${ }^{4}$. Preterm labour is defined as one where labour starts before 37 completed weeks, counting from the 1st day of last menstrual period. Though the lower limit of gestation is not uniformly defined, developed countries have brought it down to 20 weeks, whereas in developing countries it remained at 28 weeks ${ }^{5}$. Perinatal mortality has not decreased satisfactorily in spite of substantial improvements have been made in reducing perinatal mortality rate. Because issues of preterm birth are complex and causes are poorly understood, therapy is often palliative and of limited benefit. The consequences of preterm birth often far exceed the neonatal period and might impact significantly on economy of parents as well as society. Moreover, a low socio-economic condition, high birth orders especially among poor and illiterate people with high perinatal and infant mortality rate with a limited health care facility complicating the scenario $^{6}$. Data regarding perinatal mortality in developing countries derive mainly from hospital-based studies. This fact hampers a proper assessment of causes of poor perinatal outcomes because $95 \%$ of all deliveries are conducted at home 
and remaining 5\% delivered at hospitals. Hospital records of our country based on population of hospital births revealed that after exclusion of birth with congenital anomaly, preterm birth was responsible for $85 \%$ of all remaining neonatal deaths ${ }^{7,8}$. The objective of this study was to highlight the impacts of preterm labour among admitted obstetrics patients and to identify factors those contributed to preterm labour with a view to reduce perinatal mortality and morbidity. Moreover, the results of this study might contribute to gain a comparable perspective as well as to identify perinatal risks in high mortality societies.

\section{Materials and Methods}

This cross-sectional study was conducted in department of Obstetrics \& Gynaecology of SSMC Mitford Hospital, Dhaka from January 2005 to December 2005. A total of 103 cases, irrespective of parity, who got admitted with established PTL were included. Pregnancy between 28 to $<37$ completed gestational weeks with at least 1 painful uterine contraction in 10 minutes lasting for $\geq 30$ seconds and progressive cervical dilation and effacement was defined as PTL. Patients with severe pre-eclampsia, eclampsia, antepartum haemorrhage and intrauterine fetal death were excluded. All study patients were assessed by detailed relevant history and physical examination. Gestational age was confirmed either from last menstrual period, previous antenatal records or earliest ultrasonography report, as applicable. In each case, labour was monitored and managed in standard ways upto delivery. Data were collected in structured, preformed questionnaires by directly questioning, physical examination, daily follow-up of patients till their discharge and also from clinical records of patients and neonates. The obtained data were checked, verified, coded and analyzed by using SPSS software system. Data were presented as mean \pm standard deviation or frequencies and percentages as appropriate using tables.

\section{Results}

During one-year study period total 1629 patients were admitted for delivery. Of them, 1526 patients had term and 103 patients had preterm deliveries with a prevalence of preterm delivery $6.3 \%$. Mean age of study patients was 22.5 years. Majority $(62.14 \%)$ had average nutritional status and nearly half $(48.54 \%)$ completed only primary education. Majority (69.90\%) study patients were housewives and $53.40 \%$ husbands were service holders. Majorities (63.11\%) were primigravida, only $43.69 \%$ had regular ANC and $53.40 \%$ had rupture of membrane at admission. Vaginal delivery occurred in $69.90 \%$ patients and $38.84 \%$ experienced morbidity where puerperal sepsis being predominant (14.56\%). RDS was leading perinatal morbidity (24.27\%) followed by neonatal jaundice (11.65\%) and septicemia $(8.73 \%)$. Neonatal death was $32.04 \%$.
Table-I: Demographic characteristics of study patients $(n=103)$.

\begin{tabular}{|c|c|c|}
\hline Demographic variables & $\mathrm{n}$ & $\%$ \\
\hline \multicolumn{3}{|l|}{ Age group (in years) } \\
\hline $15-19$ & 12 & 11.65 \\
\hline $20-24$ & 52 & 50.49 \\
\hline $25-29$ & 25 & 24.27 \\
\hline $30-34$ & 8 & 7.77 \\
\hline $35-39$ & 6 & 5.82 \\
\hline \multicolumn{3}{|l|}{ Monthly income (in taka) } \\
\hline$<6,000$ & 23 & 22.33 \\
\hline $6,000-9,000$ & 62 & 60.19 \\
\hline$>9,000$ & 18 & 17.47 \\
\hline \multicolumn{3}{|l|}{ Nutritional status } \\
\hline Average & 64 & 62.14 \\
\hline Below average & 39 & 37.86 \\
\hline \multicolumn{3}{|l|}{ Educational status } \\
\hline Illiterate & 27 & 26.21 \\
\hline Primary & 50 & 48.54 \\
\hline SSC & 24 & 23.30 \\
\hline HSC & 2 & 1.94 \\
\hline \multicolumn{3}{|l|}{ Occupation } \\
\hline Housewife & 72 & 69.90 \\
\hline Service holder & 17 & 16.50 \\
\hline Maid servant & 13 & 12.62 \\
\hline Others & 1 & 0.97 \\
\hline \multicolumn{3}{|l|}{ Occupation of husband } \\
\hline Service & 55 & 53.40 \\
\hline Business & 29 & 28.16 \\
\hline Agriculture & 3 & 2.91 \\
\hline Others & 16 & 15.53 \\
\hline
\end{tabular}

Table-II: Obstetrics characteristics of study patients $(\mathrm{n}=103)$.

\begin{tabular}{lcc}
\hline Obstetrics variables & $\mathbf{n}$ & $\%$ \\
\hline Gravida & & \\
$\quad$ Primi & 65 & 63.11 \\
$\quad$ Multi & 38 & 36.89 \\
Antenatal check-up & & \\
$\quad$ No & 10 & 9.70 \\
$\quad$ Irregular & 48 & 46.60 \\
$\quad$ Regular & 45 & 43.69 \\
Gestational age (in weeks) & & \\
28-30 & 5 & 4.85 \\
31-34 & 51 & 49.51 \\
35-<37 completed & 47 & 45.63 \\
Previous obstetric history & & \\
Uneventful & 75 & 72.82 \\
$\quad$ Preterm labour & 16 & 15.53 \\
$\quad$ MR & 4 & 3.88 \\
Abortion & 6 & 5.83 \\
$\quad$ Perinatal death & 2 & 1.94 \\
No. of pregnancy & & \\
Singleton & 98 & 95.15 \\
$\quad$ Twin & 5 & 4.85 \\
\hline
\end{tabular}


Table-III: Membrane status at the time of hospital admission.

\begin{tabular}{lcc}
\hline Membrane status & $\mathbf{n}=103$ & $\%$ \\
\hline Ruptured & 55 & 53.40 \\
Not ruptured & 48 & 46.60 \\
\hline
\end{tabular}

Table-IV: Mode of delivery of study patients.

\begin{tabular}{|c|c|c|c|c|c|}
\hline \multirow[t]{2}{*}{ Mode of delivery } & \multicolumn{2}{|c|}{ Primigravida $(\mathrm{n}=65)$} & \multicolumn{2}{|c|}{ Primigravida $(\mathrm{n}=65)$} & \multirow{2}{*}{$\begin{array}{l}\text { Total } \\
\mathrm{n} \%\end{array}$} \\
\hline & $\mathrm{n}$ & $\%$ & $\mathrm{n}$ & $\%$ & \\
\hline ry (VD) & 42 & 40.77 & 30 & 29.13 & $72(69.9 x$ \\
\hline $\begin{array}{l}\text { Lower segment caesare- } \\
\text { an section (LSCS) }\end{array}$ & 23 & 22.33 & 8 & 7.76 & (30. \\
\hline
\end{tabular}

Table-V: Distribution of indications of caesarean section $(\mathrm{n}=31)$.

\begin{tabular}{lcc}
\hline Indications of LSCS & $\mathbf{n}$ & $\%$ \\
\hline Fetal distress & 11 & 35.48 \\
Malpresentation & 6 & 19.35 \\
Chorioamnionitis & 4 & 12.90 \\
Cervical dystocia & 3 & 9.68 \\
Occipito-posterior position & 3 & 9.68 \\
Previous caesarean section & 2 & 6.45 \\
Multiple pregnancy & 2 & 6.45 \\
\hline
\end{tabular}

Table-VI: Distribution of maternal outcomes $(n=103)$.

\begin{tabular}{lcc}
\hline Maternal outcomes & $\mathbf{n}$ & \% \\
\hline Healthy & 63 & 61.16 \\
Maternal morbidity & 40 & 38.84 \\
Puerperal sepsis & 15 & 14.56 \\
UTI & 8 & 7.77 \\
PPH & 7 & 6.80 \\
Wound infection & 6 & 5.83 \\
Retained placenta & 4 & 3.88 \\
\hline
\end{tabular}

Table-VII: Distribution of perinatal outcomes of study patients $(\mathrm{n}=103)$.

\begin{tabular}{lcc}
\hline Perinatal variables & $\mathbf{n}$ & $\mathbf{\%}$ \\
\hline APGAR score & & \\
$>7$ & 25 & 24.27 \\
$5-7$ & 40 & 38.83 \\
$\quad<5$ & 38 & 36.89 \\
Birth weight (in kg) & & \\
$\quad<2.3$ & 64 & 62.14 \\
$2.3-2.5$ & 38 & 36.89 \\
$>2.5$ & 1 & 0.97 \\
Neonatal resuscitation & & \\
$\quad$ Required & 54 & 52.42 \\
$\quad$ Not required & 49 & 47.57 \\
Referral to NICU & & \\
$\quad$ Needed & 38 & 36.89 \\
Not needed & 16 & 15.53 \\
Perinatal outcomes & & \\
Apparently healthy & 52 & 50.48 \\
RDS & 25 & 24.27 \\
Neonatal jaundice & 12 & 11.65 \\
Septicemia & 9 & 8.73 \\
Umbilical sepsis & 2 & 1.94 \\
Neonatal convulsion & 3 & 2.91 \\
Neonatal death & 33 & 32.04 \\
\hline & &
\end{tabular}

\section{Discussion}

Preterm delivery is the leading cause of perinatal mortality and morbidity and is the main risk factor for adverse pregnancy outcomes ${ }^{2,3}$. Premature infants have an increased risk of mental retardation, blindness and bronchopulmonary dysplasia 9 . The cost to society in terms of acute and chronic medical care as well as long term handicaps has made preterm delivery a serious subject for research. Till today we don't have a national statistics indicating the affection of patients with preterm labour/delivery. In majority countries of the world, estimates of incidence are principally based on hospital admission rather than total population. Therefore, it is not always possible to establish the true incidence. This study found incidence of PTL 6.3\%; whereas in India it is $10-16 \%$, in Europe $10-11 \%$, in Australia 6.8\%, in Canada and North America 9.6-11.6\% $0^{10-13}$. Although risk factors of PTL are complex, multifactorial and difficult to understand, epidemiological review have identified several risk factors $^{14-17}$. Maternal age is one of them. Pregnancy in teenagers is not quite uncommon in our country. Olansson and co-workers found an increased risk of preterm delivery among teenagers ${ }^{18}$. Though this study encompassed a wide-ranged age groups but half of study women $(50.49 \%)$ with PTL was of 20-24 years with a mean age 22.5 years. Iams et al. found mean age 25 years ranging from 14 to 39 years ${ }^{19}$. Socio-economic status is indirectly reflected through education, occupation and monthly income of the family. Most of the study patients $(73.79 \%)$ at least completed primary education (Table I). This might reflect the influence of female education in creating awareness and seeking early obstetric care before any serious complication arises. Though the incidence of PTL found to be slightly higher in middle socio-economic group having monthly income 6,000-9,000 taka, this needs to be verified further. One consistent major risk factor for PTL is prior history of preterm birth. The recurrence rate in this study was $15.53 \%$ compared to $21 \%$ shown by Naeye ${ }^{20}$. Occurrence of abortion or MR in previous pregnancy may increase the risk of PTL in current pregnancy. In this study, 5.83\% and $3.88 \%$ patients gave a history of previous abortion and MR respectively. The association between PTL and prior preterm birth may be due to some biological and genetic factors those to be determined or may be due to infection or cervical injury during previous operative interference. Almost half of study patients (49.51\%) had 31-34 gestational weeks with singleton pregnancy $(95.15 \%)$ and ruptured membrane $(53.40 \%)$. (Table II \& III) Two-thirds of study patients $(69.90 \%)$ delivered vaginally whereas one-third $(30.09 \%)$ needed caesarean section. (Table IV) The commonest indication of LSCS being foetal distress (35.48\%) followed by malpresentation (19.35\%). Chorioamnionitis ranked third (12.9\%). (Table V) Maternal morbidity following PTL seems to be relatively high many folds due to increased operative interference and frequent association of puerperal infection of several kinds. Though this study found no maternal mortality, 38.84\% patients experienced morbidity in various forms. Puerperal sepsis 
was found to be the leading maternal morbidity (14.56\%) followed by UTI $(7.77 \%)$, PPH $(6.80 \%)$, wound infection $(5.83 \%)$ and retained placenta $(3.88 \%)$. (Table VI) Several studies also support these findings ${ }^{3,7,19,20}$. Regarding perinatal outcomes, $62.14 \%$ babies had birth weight $<2.3 \mathrm{~kg}$, $52.42 \%$ required resuscitation and $36.89 \%$ needed NICU referral. Though $50.48 \%$ babies were born apparently healthy, $32.04 \%$ mothers had perinatal deaths during their hospital stay. Perinatal morbidity was encountered in $49.51 \%$ study patients, of which respiratory distress syndrome (RDS) topped in the list $(24.27 \%)$ followed by neonatal jaundice $(11.65 \%)$, septicemia $(8.73 \%)$, umbilical sepsis $(1.94 \%)$ and neonatal convulsion $(2.91 \%)$. (Table VII) Many other studies found similar findings, ${ }^{2,7,9,11}$ although dissimilarities are not scarce ${ }^{3,20}$.

\section{Conclusion}

Preterm labour was found to be associated with several maternal morbidities like puerperal sepsis, UTI, PPH, wound infection and retained placenta. Along with neonatal mortality this study also found to contribute in a wide range perinatal morbidity like low birth weight, increased need of NICU, RDS, neonatal jaundice, septicemia, umbilical sepsis and neonatal convulsion. So, this study concludes that preterm labour adversely affect the health outcomes of both mother and newborns.

\section{Conflict of Interest: None.}

Acknowledgement:

We acknowledge the help of the staff of department of Obstetrics and Gynecology, SSMC Mitford hospital for their unpaid support and cooperation at every step of this study.

\section{References:}

1. R. Lamont, P. Husslein. Introduction. BJOG. 2003 April; 110 (suppl 20): Pl.

https://doi.org/10.1046/j.1471-0528.2003.00001.x

2. Rush RW, Kierse MJNC, Howat P, Anderson ABM, Turnbull AC. Contribution of preterm delivery to perinatal mortality. Br Med J. 1976; 2(6042):965-8.

https://doi.org/10.1136/bmj.2.6042.965

3. Arias F, Tamich P. Etiology and outcome of low birth weight and preterm infants. Obstet Gynecol. 1982; 60:277-81.

4. Aris F. Practical guide to high-risk pregnancy and delivery 2nd edition. Bangalore: Harcourt Brace and company Asia pte. Ltd; 1999.

5. Dutta DC. Textbook of Obstetrics, 6th edition. Calcutta: New central book agency (P) Ltd; 2005, P314.

6. Decherney AH, Pernoll ML. Current Obstetrics and Gynaecological Diagnosis and Treatment. 9th edition Oxford. Appleton and Lange; 2002.
7. Ferdousi B, Nargis S. Perinatal outcome in preterm labour. Bang J of Obstet Gynaecol. 2000; 15(2):65-72.

8. National vital statistics report 2002; 50: No. 5.

9. Rush RW, Davey DA. Segall ML. The effect of preterm delivery on perinatal mortality. Br J Obstet Gynaecol. 1978; 85:806-11.

https://doi.org/10.1111/j.1471-0528.1978.tb15833.x

10. Philip S. Epidemiology of preterm labour. BJOG. 2005 Mar; 112 (issue-s1) P1.

https://doi.org/10.1111/j.1471-0528.2005.00575.x

11. Alberman E, Evans SJW. Epidemiology of prematurity: Aetiology, prevalence and outcome. Annales Nestle June. 1989; 47(2):69-88.

12. Blondel B, Du Manzan Brun E, Breast G. Enquen Nationale perinatale, 1995. Report defind clude. Inser Inserm edition. Paris Inserm. 1996.

13. Kramer MS, Platt R, Yang H. Secular trends in preterm birth: a hospital based cohort study. JAMA. 1998; 280:1849-1954.

https://doi.org/10.1001/jama.280.21.1849

14. Mis PJ, Brnest JM, Moore ML. Causes of low birth weight in public and private patients. Am J obstet Gynecol. 1987; 156:1165-8.

https://doi.org/10.1016/0002-9378(87)90133-5

15. Weidinger H, Weist WA. Comparative study of epidemiological data of pregnancies with and without tendencies to premature delivery. J Perinat Med. 1976; 2:276-87.

https://doi.org/10.1515/jpme.1974.2.4.276

16. Kaltreidu DF, Kohl S. Epidemiology of preterm delivery. Clin obstet Gynecol. 1980; 23:14-30.

https://doi.org/10.1097/00003081-198003000-00005

17. Shalev E. Epidemiologic risk factors for preterm delivery. IMAJ. 2002 Dec; 4:1115-17.

18. Olansson PO, Chattingius S, Agluad B. Does the increased risk of preterm delivery in teenagers persist in pregnancies after the teenage period? Br J Obstet Gynaecol. 2001; 108:721-5.

https://doi.org/10.1016/S0306-5456(00)00182-0

19. Iams JD, Stilson R, Johnson FF, Williams RA. Factors that precede preterm labour and preterm premature rupture of the membranes. Am J Obstet Gynaecol. 1990; 162:486.

https://doi.org/10.1016/0002-9378(90)90417-6

20. Naeye RL, Peters EC. Causes and consequences of premature rupture of foetal membranes. Lancet. 1980; $1: 192$.

https://doi.org/10.1016/S0140-6736(80)90674-1 